Research Article

\title{
Electromagnetic Design and Flux Regulation Analysis of New Hybrid Excitation Generator for Electric Vehicle Range Extender
}

\author{
Wenjing Hu, Xueyi Zhang (iD, Huihui Geng, Ting Gao, Liwei Shi, and Di You \\ School of Transportation and Vehicle Engineering, Shandong University of Technology, Zibo 255049, China \\ Correspondence should be addressed to Xueyi Zhang; zhangxueyi@sdut.edu.cn
}

Received 30 January 2021; Revised 7 March 2021; Accepted 17 March 2021; Published 27 March 2021

Academic Editor: Massimo Brignone

Copyright ( $\odot 2021$ Wenjing Hu et al. This is an open access article distributed under the Creative Commons Attribution License, which permits unrestricted use, distribution, and reproduction in any medium, provided the original work is properly cited.

\begin{abstract}
Aiming at the problem of uncontrollable magnetic field of permanent magnet generators, a new hybrid excitation generator (HEG) with parallel magnetic circuit is proposed. The HEG consists of combined permanent magnet rotor (PMR) and brushless electric excitation rotor (EER). The PMR has surface-mounted and embedded magnets. The PMR provides the main air gap field, and the brushless EER is used to adjust the air gap field. The operating principle and electromagnetic design scheme of the proposed generator are given in detail. Besides, the matching with two different types of rotors and the flux regulation characteristics is analyzed by using the finite element method. Finally, the output performance of the proposed generator including noload and load characteristics and output voltage are tested. The results show that the two different types of rotors can be matched efficiently and operated reliably. The internal magnetic flux is easy to adjust in both directions, and the proposed HEG can output stable voltage in the range of wide speed and load.
\end{abstract}

\section{Introduction}

Extended-range electric vehicles (EREV) have become one of the main directions of the development of new energy vehicles due to the following: energy saving, low pollution, and increase in the longer endurance mileage $[1,2]$. Range extender (ER) is a small auxiliary power unit of the EREV. The generator is the key component of the ER [3]. Since the installation space of the generator for ER is limited, it is more important to improve the output power and efficiency under the premise that the generator volume remains unchanged. In addition, due to the wide range of engine speed for ER, the generator output voltage is low when the speed is low, and the generator output voltage is high when the speed is high, which affects the normal work of electrical equipment $[4,5]$. So, it has become the focus of our research to design a generator with high power density and stable output voltage under wide speed and wide load.

Traditional electric excitation generators (EEGs) have the characteristics of easy magnetic field adjustment and good power factor controllability. However, there are risks of complex structure, large excitation loss, and excessive temperature rise due to brushes and field winding $[6,7]$. Permanent magnet generators (PMGs) have the advantages of simple structure, high efficiency, low loss, and high power density, and they are widely used in fields of aerospace, national defense, and industrial and agricultural production. However, the application of the PMG in some specific occasions is limited because of the nonadjustable magnetic field $[8,9]$. In order to integrate the advantages of EEG and PMG and overcome their shortcomings, the hybrid excitation generator (HEG) is studied. In the HEG, the field winding is placed in the PMG. The field winding is used to assist in the adjustment of the permanent magnet (PM) magnetic field. So, the HEG has the characteristics of high power density and adjustable magnetic field, and it has attracted wide attention [10-12].

Many scholars have made a lot of research studies on the HEGs. Liu et al. [13] proposed a HEG with series magnetic circuit. Comparing with other types of HEG, the structure of machine is simpler. However, the magnetic potentials by the PMs and excitation winding are in series, which increases the magnetic circuit reluctance and causes irreversible demagnetization of PMs. Cai et al. [14-16] proposed the HEG with 
iron core poles and PM poles alternately arranged. The auxiliary ring excitation winding is located in the stator core and the air gap magnetic field is adjustable. However, the iron core poles and PM poles have the same axial length, and the power density is lower. Gaussens et al. [17-21] studied a hybrid excitation flux-switching generator in which the excitation winding is put into a flux-switching PMG. The air gap magnetic field of the generator is easy to adjust. However, the space of the stator is tight and the space utilization is reduced because the PMs, excitation winding, and armature winding are all located in the stator. Wang et al. [22-25] proposed a combined rotor HEG, and by adding the magnetic bridge, the electromagnetic and PM field are in parallel in the air gap. Due to the existence of the magnetic bridge, the axial length and loss of the HEG are rapidly increasing.

Through reading the above references, the author found that combined PMGs have strong magnetization ability and high air gap magnetic density [22, 26-28]. In addition, the brushless EEGs have good air gap field adjustment ability and high reliability [29-31]. Based on the advantages of the above two kinds of generators, this paper proposes a new type of parallel magnetic circuit hybrid excitation generator (PMCHEG). The permanent magnet rotor (PMR) and the electric excitation rotor (EER) are installed side by side on the same shaft. The PMCHEG can not only retain the inherent characteristics of PMG to the greatest extent but also inherit the performance of field regulation of EEG, which has high research and practical value. In this paper, the working principle and the design scheme of the PMCHEG are given in detail. In order to make two different types of rotors efficiently match the operation, the phase electromotive force waveform optimization scheme is researched. Meanwhile, the flux regulation characteristics and the output performance of the PMCHEG are analyzed and verified by the simulation software and prototype test.

\section{Topology and Operating Principle of the PMCHEG}

The PMCHEG mainly includes PMR, EER, two stators, and a set of armature winding and field winding, providing electrical energy for vehicle electrical equipment and charging the battery. In the PMCHEG, the PMR and the EER are installed side by side on the same shaft. The structure of the proposed PMCHEG is shown in Figure 1, and the main technical indicators are shown in Table 1.

There are two main magnetic flux paths in the PMCHEG : PM magnetic flux path, and forward (or reverse) electric excitation flux path is shown in Figure 2.

The PM magnetic flux is provided by the PMR. The magnetic potential under each pole is provided by one tangential PM (TPM) and two adjacent radial PMs (RPM) together. As shown in Figure 2(a), the specific PM magnetic flux path is $\mathrm{N}$ pole of TPM $\longrightarrow$ rotor core of the PMR $\longrightarrow$ RPM $\mathrm{I} \longrightarrow$ pole shoe $\mathrm{I} \longrightarrow$ air gap $\longrightarrow$ stator teeth $\longrightarrow$ stator yoke $\longrightarrow$ stator teeth $\longrightarrow$ air gap $\longrightarrow$ pole shoe $\mathrm{II} \longrightarrow \mathrm{RPMII} \longrightarrow$ rotor core of the PMR $\longrightarrow \mathrm{S}$ pole of TPM. The magnetic field generated by TPM and RPMs are combined in series in the air gap. On the contrary, the ability of magnetic gathering is improved, which can improve the power density of the PMCHEG in the pure permanent magnet excitation state. On the contrary, the RPM is arranged between the outer ends of two adjacent TPMs. The RPM can make up for the dent of the original air gap magnetic density waveform. It makes the air gap magnetic density sinusoidal. At the same time, it can also effectively reduce the distortion rate of voltage waveform.

The forward (or reverse) electric excitation flux path is provided by the EER. As shown in Figure 2(b), the specific forward electric excitation flux path is $\mathrm{N}$ pole of field winding $\longrightarrow$ yoke of claw pole $\mathrm{I} \longrightarrow$ body of claw pole $\mathrm{I} \longrightarrow$ stator teeth $\longrightarrow$ stator yoke $\longrightarrow$ stator teeth $\longrightarrow$ body of claw pole II $\longrightarrow$ yoke of claw pole II $\longrightarrow$ S pole of field winding, forming a closed loop. When the excitation current is less than zero, the direction of the excitation current is opposite, and the air gap flux generated by the field winding is reversed, as shown in Figure 2(c). The equivalent magnetic circuit models of synthetic magnetic field under different excitation directions are shown in Figure 3. $\Phi_{\mathrm{pm}}$ and $\Phi_{\mathrm{em}}$ are the main fluxes generated by the PM and field winding. $\Phi_{\mathrm{lpm}}$ and $\Phi_{\text {lem }}$ are the leakage fluxes generated by the PM and field winding. $F_{\mathrm{pm}}$ and $F_{\mathrm{em}}$ are the equivalent magnetic potential sources of the PM and field winding. $G_{\mathrm{pm}}$, $G_{\text {em }}, G_{\text {air }}$, and $G_{\mathrm{s}}$ are the equivalent magnetic conductivity of the PM, field winding, air gap, and stator. $G_{\mathrm{lpm}}$ and $G_{\mathrm{lem}}$ are the equivalent leakage magnetic conductivity of the PM flux and electric excitation flux path. PM and electromagnet flux are independent of each other. When changing the magnitude and direction of the excitation current, the size and direction of the air gap flux generated by the EER will be changed. In other words, the change of excitation current can realize effective adjustment of the induced electromotive force (EMF) of the PMCHEG.

\section{Electromagnetic Design of PMCHEG}

3.1. Combined PMR. The combined PMR is composed of eight parts: rotor core, shaft, screws, die-cast aluminum magnetic isolation bushing, tangential PMs, radial PMs, pole shoes, and iron rivets. The pole shoes and RPMs are fixed on the outer surface of the rotor core by screws. The die-cast aluminum magnetic isolation bushing is used to avoid the magnetic leakage in the shaft end. TPMs are embedded in the rotor core. The rotor core is fitted on the shaft through the magnetic isolating bushing. The structure and main electromagnetic parameters of the combined PMR are shown in Figure 4. Two adjacent embedded TPMs can concentrate magnetism. Radial surface-mounted PMs are fixed by screws to avoid the risk of falling off at high speed.

Calculate the total volume of PMs according to the external characteristics of the PMCHEG:

$$
V_{P M}=K_{k}^{2} K_{b k} \times \frac{p \sigma_{0} n P_{N}(\cos \phi=0)}{240 K_{f}\left(K_{k}-1\right)(B \cdot H)_{\max }} \times 10^{6}
$$

where $K_{k}$ is the short circuit current multiple, $p$ is the number of pole pairs, $\sigma_{0}$ is the no-load magnetic flux leakage coefficient, $\alpha$ is the polar arc coefficient, $n$ is the rated speed, $P_{N}$ is the apparent power, $(B \cdot H)_{\max }$ is the maximum energy 


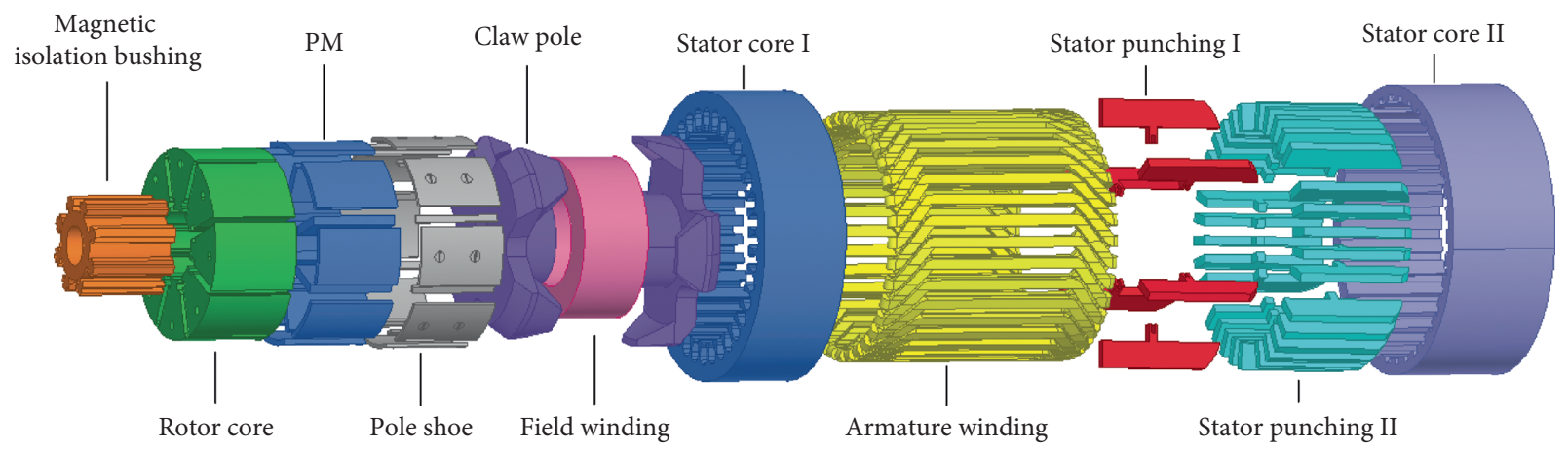

Figure 1: The structure of the proposed PMCHEG.

TABLE 1: Main technical indexes of the proposed PMCHEG.

\begin{tabular}{lc}
\hline Index & Value \\
\hline Rated voltage $(\mathrm{V})$ & 28 \\
Rated power $(\mathrm{W})$ & 500 \\
Rated speed $(\mathrm{r} / \mathrm{min})$ & 4000 \\
Number of phases & 3 \\
Insulation class & $\mathrm{E}$ \\
Protection level & IPX4 \\
Cooling type & Wind cooling \\
Output type & DC \\
\hline
\end{tabular}

product, $K_{b k}$ is the coefficients related to PM operating point, magnetic circuit saturation and pole arc coefficient, and $K_{f}$ is the air gap magnetic density waveform coefficient, $K_{f}=4 \sin (\alpha \pi / 2) / \pi$.

By calculating the magnetic potential provided by the PMS to the external magnetic circuit, we can calculate the specific size of the PMS, as shown in Equations (2) and (3). The PM flux trend of a pair of magnetic pole is shown in Figure 2(a). The structural dimensions of PMs are shown in Table 2:

$$
\begin{aligned}
& b_{M}=\frac{F_{M}}{H_{M}}=\frac{2 K_{a} K_{s} K_{\delta} \delta B_{\delta}}{\mu_{0} H_{M}}, \\
& h_{M}=\frac{2 p V_{P M}}{b_{M} \pi D^{2} \lambda},
\end{aligned}
$$

where $b_{M}$ is the thickness of PM, $h_{M}$ is the width of PM, $F_{M}$ is the magnetic potential of the external magnetic circuit of each pole, $H_{M}$ is the magnetic field intensity of the PM working point prefetched according to the magnet demagnetization curve strength, $K_{a}$ is the coefficient that the magnetic potential of the PM should be increased to overcome the demagnetization effect of the armature reaction, $K_{s}$ is the magnetic circuit saturation coefficient, $K_{\delta}$ is the air gap coefficient, $\delta$ is the air gap length, $B_{\delta}$ is the air gap magnetic induction intensity, $D$ is the inside diameter of the armature windings, $\lambda$ is the aspect ratio of the armature windings, and $\mu_{0}$ is the permeability of the vacuum, $\mu_{0}=4 \pi \times 10^{-7} \mathrm{H} / \mathrm{m}$.

3.2. Brushless Claw Pole EER. The main function of the EER is to change additional magnetic field by changing excitation current. It can compensate the voltage change of the PMG due to the change of the load current. Furthermore, it can also keep the output voltage stable. The brushless claw pole EMR mainly consists of claw pole I, claw pole II, iron hoop, field winding, and shaft. The field winding is tied together by six iron hoops, and then, the ends of iron hoops are welded to the stator punching II. The field winding is suspended between the two claw poles to achieve the brushless excitation. When the two brushes are energized, the field winding generates the axial magnetic flux. One of claw poles is magnetized into $\mathrm{N}$ pole and the other is magnetized into $\mathrm{S}$ pole, forming N/S alternating magnetic poles. The structure of brushless claw pole EER is shown in Figure 5.

The cross sections of the claw pole are trapezoid with unequal areas. The air gap magnetic induction intensity not only changes along the circumference of the EER but also changes along the axis of the EER. In the design of the claw pole rotor, the fundamental wave of the air gap field should be as large as possible. However, the amplitude of other harmonics should be as small as possible. In order to facilitate the analysis, the following assumptions are given: (1) ignore the effect of magnetic saturation and (2) ignore the axial magnetic leakage.

The axial magnetic flux of any cross section can be expressed:

$$
\Phi_{a x}(\theta)=\Phi_{0} \frac{x}{L_{c}-x}
$$

Magnetic flux density:

$$
\begin{aligned}
B_{a x}(\theta) & =\frac{\Phi_{a x}(\theta)}{S_{a x}}=\Phi_{0} \frac{x}{L_{c} S_{a x}} \\
& =\Phi_{0} \frac{2 x}{L_{c}\left(b_{\max }+b_{\min }\right)\left(x \tan \beta+h_{c 2}\right)},
\end{aligned}
$$

where $\Phi_{0}$ is the total magnetic flux, $S_{a x}$ is the area of the selected cross section, $x$ is the length from the selected cross section to the claw tip, $L_{c}$ is the length of claw pole, $b_{\max }$ and $b_{\min }$ are the maximum and minimum claw pole width of the selected cross section, respectively, $h_{c 2}$ is the thickness of the claw tip, and $\beta$ is the inclination angle of the inner surface of the claw pole.

The amount of flux transferred between the stator and EER can be significantly adjusted. When the inclination angle of the inner surface of the claw pole is changed, the 


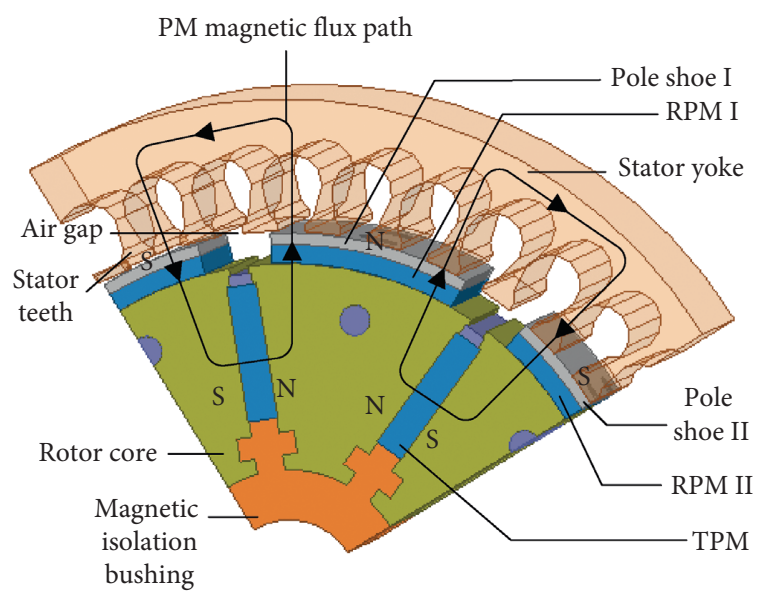

(a)

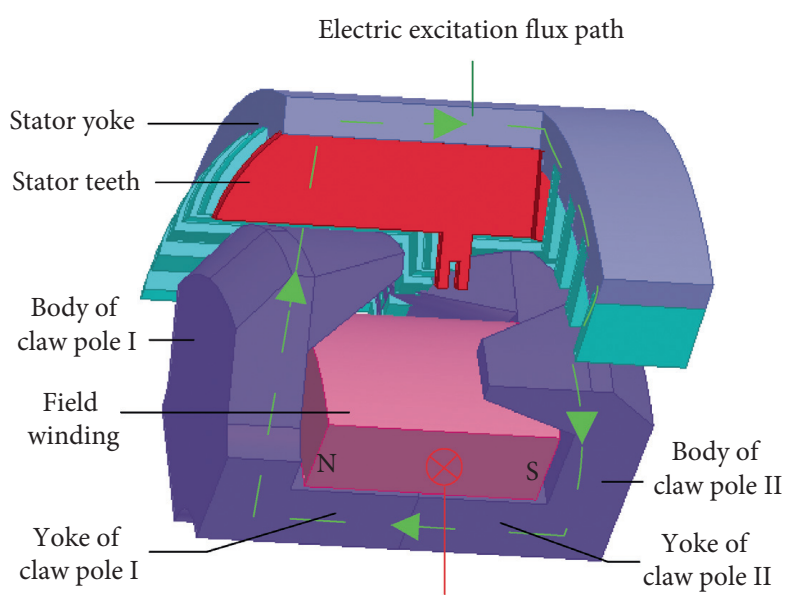

Extation current direction: point in of terminal

(b)

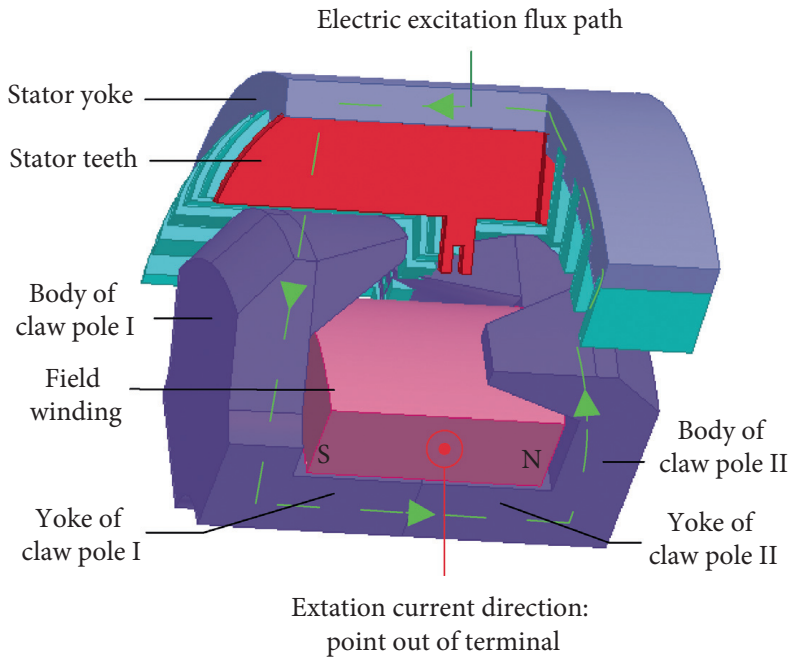

(c)

FIGURE 2: Magnetic flux paths of the PMCHEG. (a) PM magnetic flux path. (b) Electric excitation flux path with forward current. (c) Electric excitation flux path with reverse current.

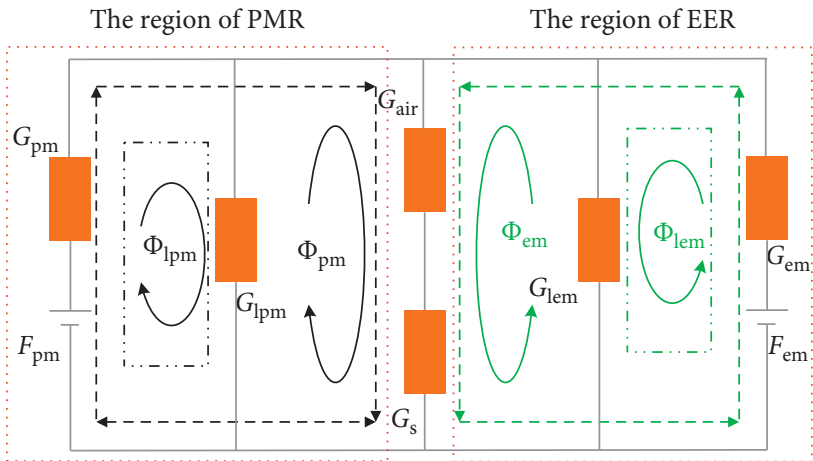

(a)

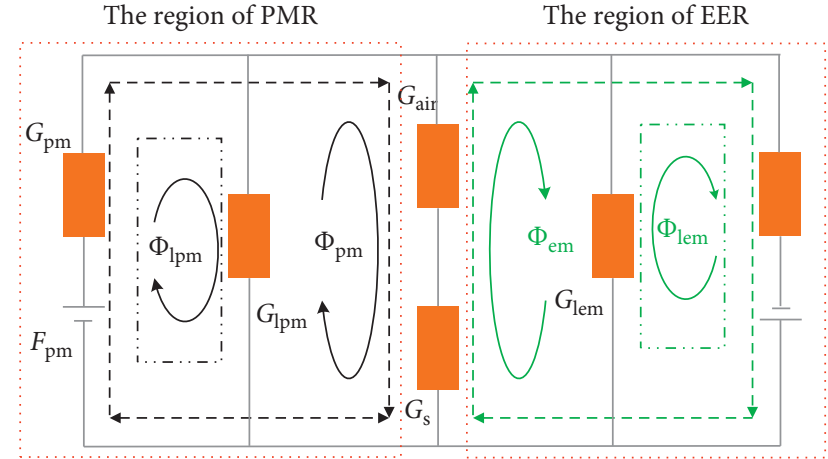

(b)

FIGURE 3: Equivalent magnetic circuit model of synthetic magnetic field. (a) With forward excitation current. (b) With reverse excitation current. 


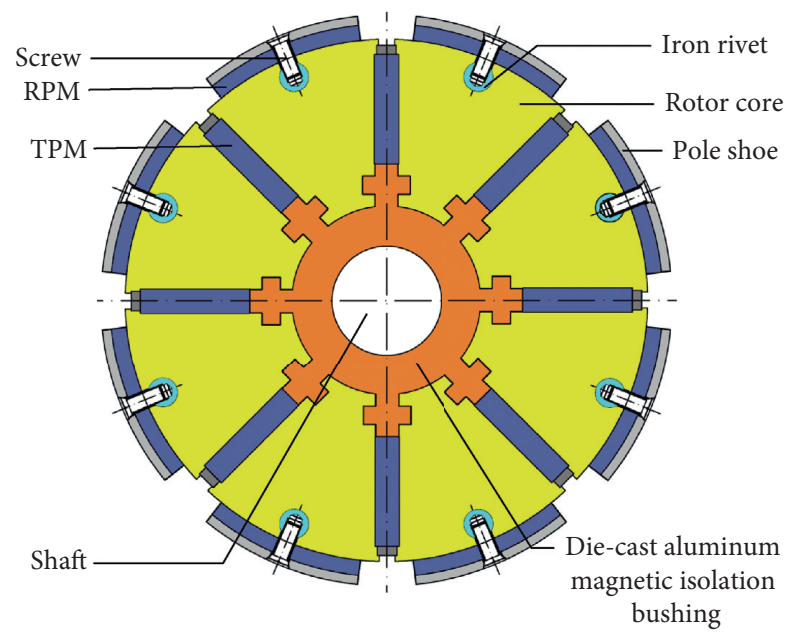

(a)

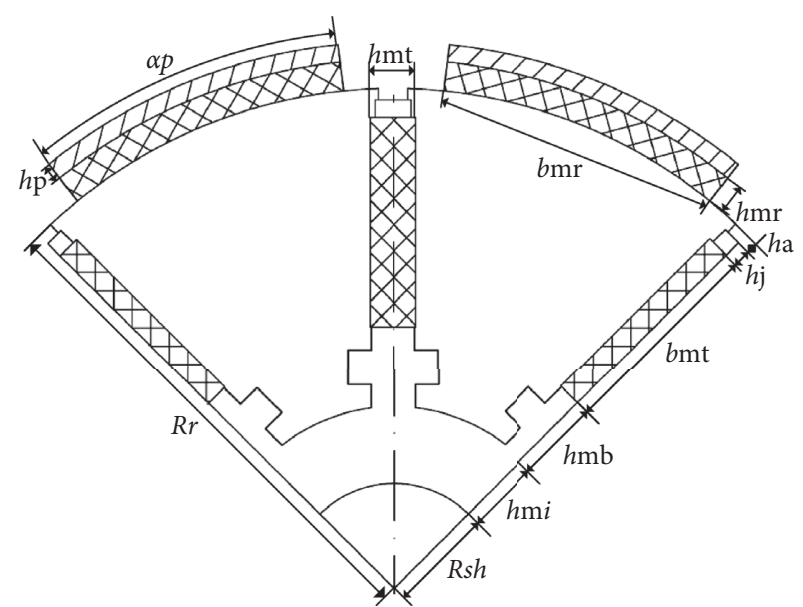

(b)

Figure 4: The combined PMR. (a) The structure of combined PMR. (b) The electromagnetic parameters of combined PMR.

TABLE 2: Structural dimensions of the combined PMR.

\begin{tabular}{lccc}
\hline Parameter & Thickness $(\mathrm{mm})$ & Width $(\mathrm{mm})$ & Length $(\mathrm{mm})$ \\
\hline TPM & 4 & 18.5 & 20 \\
RPM & 2.5 & 25 & 20 \\
\hline
\end{tabular}

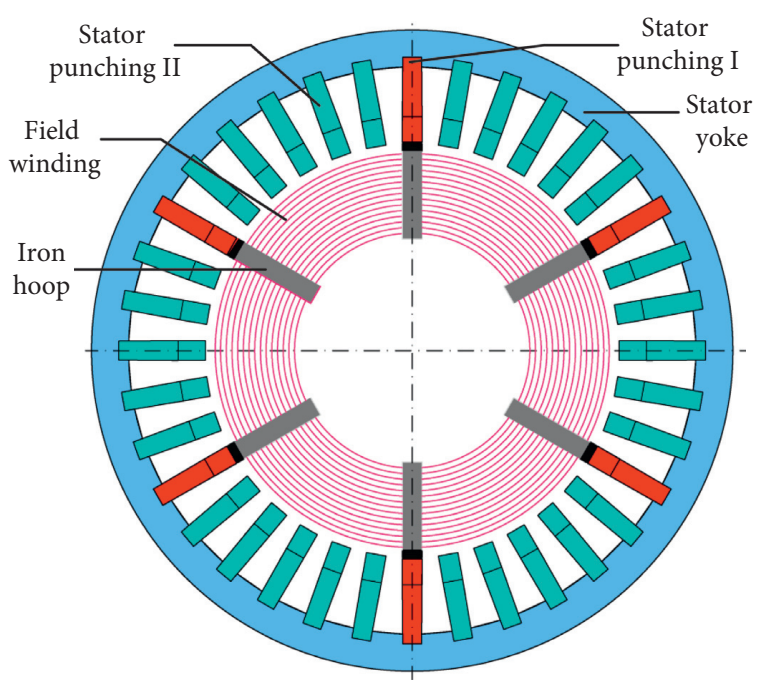

FIGURE 5: The structure of brushless claw pole EER.

content of leakage flux and the harmonic of the air gap field can be significantly adjusted. Figure 6 shows the dimension of the claw pole and the selected cross section. $h_{c 1}$ represents the thickness of the claw heel, $b_{c 1}$ represents the width of the claw tip, $b_{c 2}$ represents the width of the claw heel, and $h_{f}$ represents the thickness of the radial magnetic yoke.

When $\beta$ is between $10.5^{\circ}$ and $11.7^{\circ}$, the fundamental wave amplitude of the air gap magnetic density is high, and the high-order harmonic content of the induced EMF is low. When $\beta$ is too large or too small, there will be high-order harmonic to affect the performance of the generator. The side surface of the claw pole is a right-angled trapezoid.

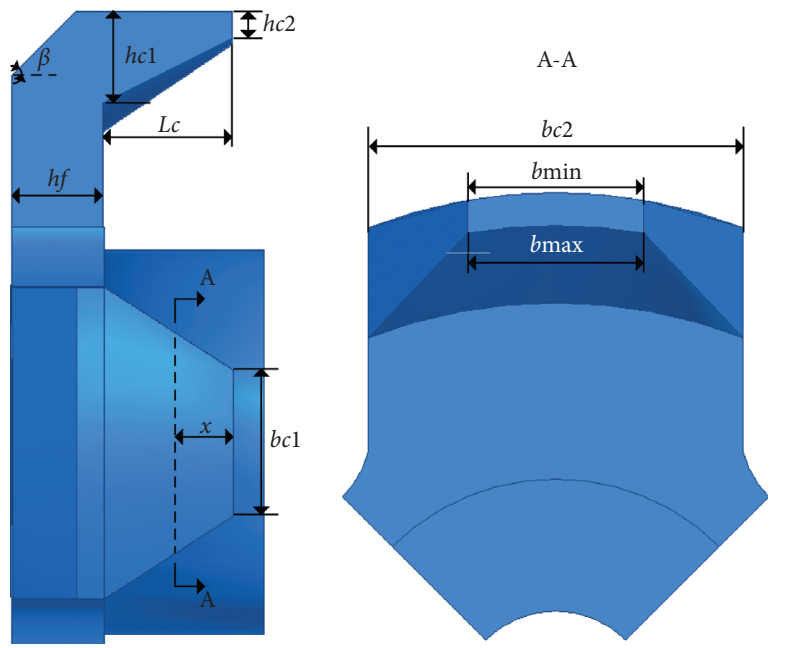

FIGURE 6: Claw pole size relationship diagram.

According to the geometric relationship of the right-angled trapezoid, the relationship between the thickness of the claw pole heel and the claw pole tip can be obtained:

$$
\left\{\begin{array}{l}
h_{c 1}-h_{c 2}=L_{c} \tan \beta \\
h_{c 2}=(0.3 \sim 0.5) h_{c 1}
\end{array}\right.
$$

If the thickness of the claw pole palm is too small, the magnetic density of the pole body will be easily saturated. If the thickness of the claw pole palm is too large, the space where the field winding is placed is too narrow. Table 3 shows the structural dimensions of the EER.

According to Kirchhoff's second law [32], 
TABLE 3: Structural dimensions of the EER.

\begin{tabular}{lc}
\hline Claw pole parameter & Value $(\mathrm{mm})$ \\
\hline The length of claw pole & 7.5 \\
The thickness of radial magnetic yoke & 6.5 \\
The length of axial magnetic yoke & 8.5 \\
The diameter of axial magnetic yoke & 39 \\
Pole arc at the claw tip & 0.4 \\
Pole arc at the claw heel & 0.8 \\
Claw tip thickness & 2.4 \\
Claw heel thickness & 6 \\
\hline
\end{tabular}

$$
\frac{B_{1}}{\mu_{0}} \times l_{1}+\frac{B_{2}}{\mu_{r 2} \mu_{0}} \times l_{2}+\frac{B_{3}}{\mu_{r 3} \mu_{0}} \times l_{3}=N I_{e}
$$

where $B_{1}$ is the magnetic flux density in the air gap, $B_{2}$ is the magnetic flux density in the stator silicon lamination, $B_{3}$ is the magnetic flux density in the claw pole, $l_{1}$ is the magnetic circuit length in the air gap, $l_{2}$ and $\mu_{r 2}$ are the magnetic circuit length in the silicon laminations and relative permeability of the silicon laminations, $l_{3}$ and $\mu_{r 3}$ are the length in the magnetic circuit in the claw poles and the relative permeability of the claw poles, $N$ is the number of turns of the field winding, and $I_{\mathrm{e}}$ is the current of the field winding.

Diameter of electric excitation winding $d_{e}$ is calculated as

$$
d_{e}=\sqrt{\frac{4 I_{\mathrm{e}}}{\pi J}},
$$

where $J$ is the current density of electric excitation winding.

3.3. Stator Structure. The stator in the PMR is made by laminating ordinary silicon steel sheets axially. Compared with the stator of the PMR, the structure of EER is complex. Considering the installation of hoop and transfer of axial and radial magnetic flux, a combine stator with less eddy current loss is designed. In order to meet the demand of fixed iron hoop, there are two kinds of stator teeth. The combine stator consists of the stator teeth with iron hoop and without iron hoop and the stator yoke. The stator teeth is used to transmit radial magnetic flux and the stator yoke is used to transmit axial magnetic flux. The structure of the combine stator is shown in Figure 7.

\subsection{Optimization of Induced EMF Waveform. Although} there are two different stators in the PMCHEG, the armature windings are wound after the two stators are welded together and the PMR and the EER share a set of armature windings. The induced EMF of the PMCHEG is the sum of that generated by the PMR and the EER. The quality of the total EMF is affected not only by the amplitude of the EMF of the PMR and the EER but also by the coupling degree of the EMF of the PMR and the EER. Furthermore, the sine of the phase EMF waveform generated the combined PMR is different from that of the EER. Therefore, in order to ensure the efficient superposition of two kinds of EMF, it is necessary to study the optimal matching scheme of the phase EMF waveform in the two parts further.

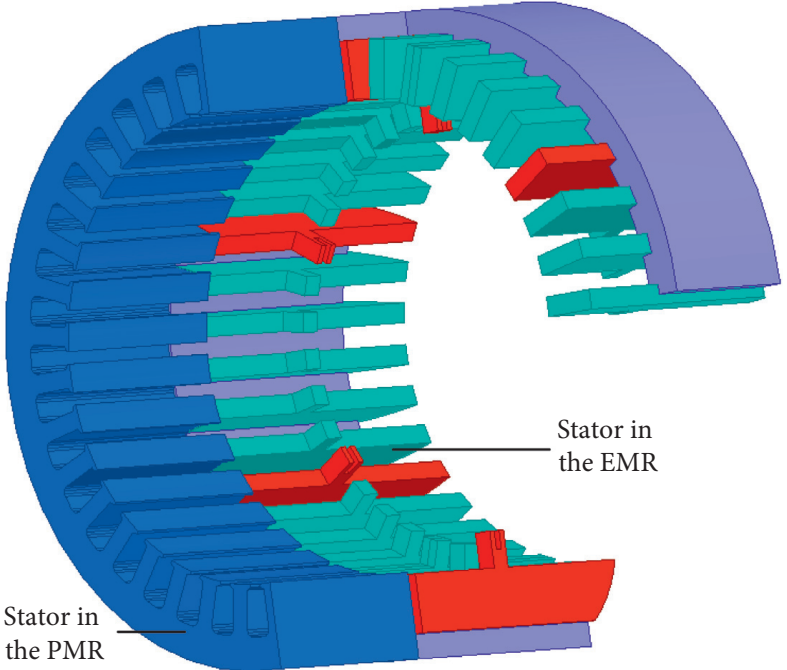

Figure 7: The structure of the stator of the PMCHEG.

The centerlines of all magnetic poles of the PMR and EER are aligned. Because the PMR adopts combined magnetic pole, the waveform of induced EMF is almost sinusoidal. However, in the EER, there are two pole arc coefficients including the claw tip and the claw heel. The special magnetic pole causes serious waveform distortion rate in the EMF of the EER, which is quite different from the sine wave of the EMF generated by the PMR. Table 4 lists the polar arc coefficients of the claw heel and the width of the claw tip and the claw heel under different the claw tip pole arcs.

Figure 8 shows the fundamental and harmonic amplitude of the phase induced EMF under the different claw tip pole arc coefficients. With the increase of the claw tip pole arc coefficient, the fundamental and harmonics amplitude of the EMF rise slowly and then decrease quickly. When the claw tip pole arc coefficient is between 0.35 and 0.50 , the fundamental amplitude is larger and the high harmonic content is lower. Figure 9 shows the waveform of the induced EMF under the different claw tip pole arcs. With the increase of the claw tip pole arc coefficient, the waveform tends to be smooth and sinusoidal, but the curve is in a downward trend. Because the PMR adopts the combined magnetic pole, the induced EMF tends to a sine curve, as shown in Figure 10. Comparing the waveform of the induced EMF generated by the EER and the PMR, we can find that the degree of coupling between the two kinds of EMF changes with the claw tip pole arc coefficient. When the claw tip pole arc coefficient is 0.45 , the degree of field coupling is the greatest. The induced EMF of the two parts can be easier to achieve high efficiency superposition. The induced EMF generated by the PMR and EER are similar to sinusoidal wave, which verifies that the PMCHEG is suitable for the generator for electric vehicle range extender.

\section{Finite Element Magnetic Field Simulation}

4.1. Finite Element Model. In order to verify the rationality of the electromagnetic design and study the characteristics of field regulation of the PMCHEG, the three-dimensional 
Table 4: Parameters of the claw pole with different claw tip pole arcs.

\begin{tabular}{lccc}
\hline Pole arc at the claw tip & Claw tip width $(\mathrm{mm})$ & Pole arc at the claw heel & Claw heel width (mm) \\
\hline 0.35 & 13 & 0.65 & 24 \\
0.40 & 15 & 0.70 & 26 \\
0.45 & 17 & 0.75 & 28 \\
0.50 & 18 & 0.80 & 29 \\
0.55 & 20 & 0.85 & 31 \\
0.60 & 22 & 0.90 & 33 \\
\hline
\end{tabular}

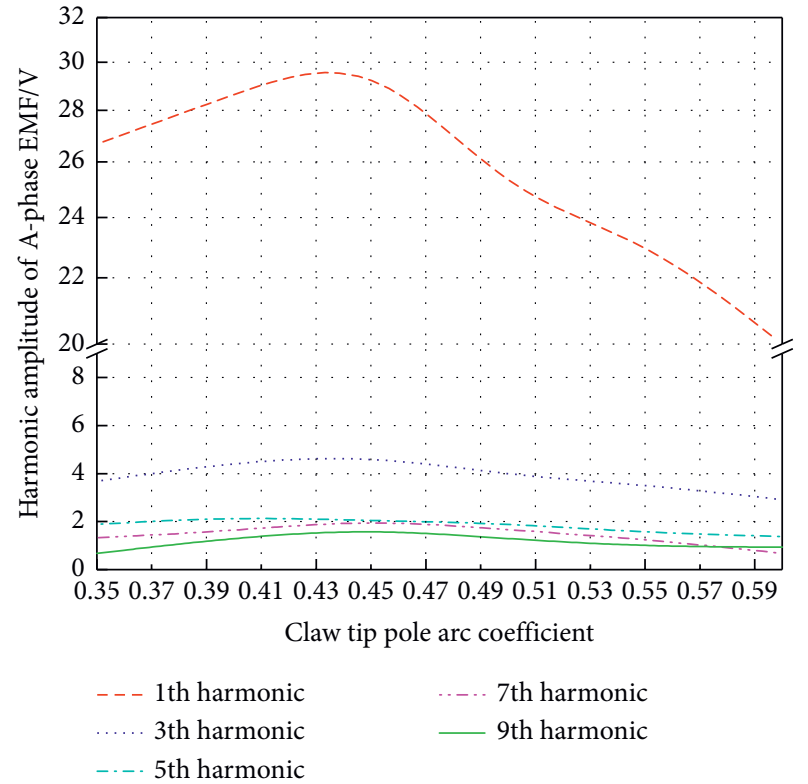

FIGURE 8: The fundamental and harmonic amplitude of the phase EMF.

model of the PMCHEG is established by using finite element software. Because the structure of the HEG is symmetrical,

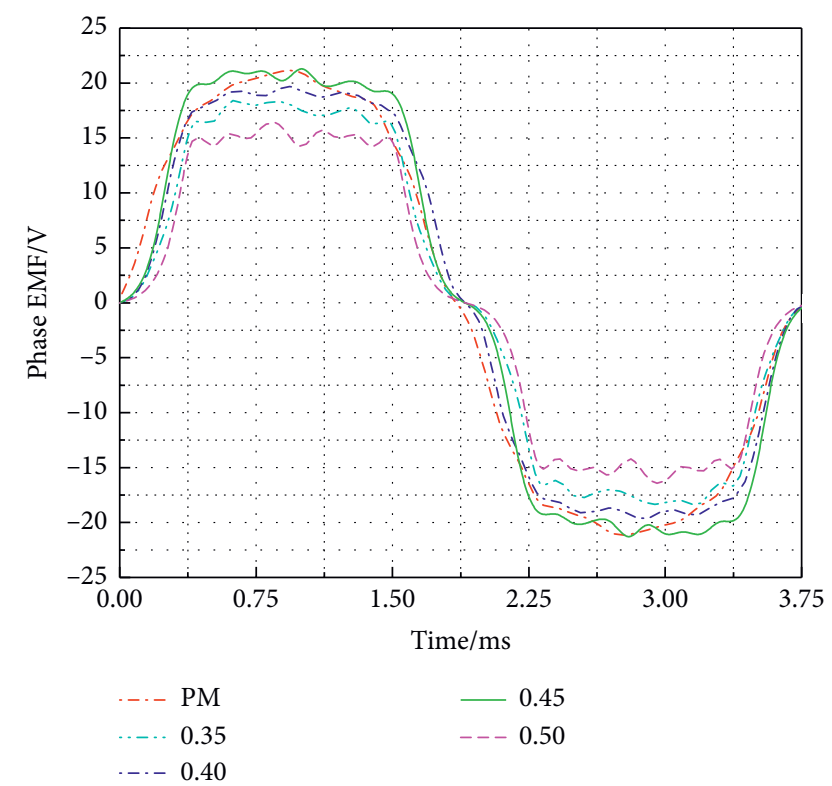

FIGURE 9: The waveform of induced EMF with the different claw tip pole arcs.

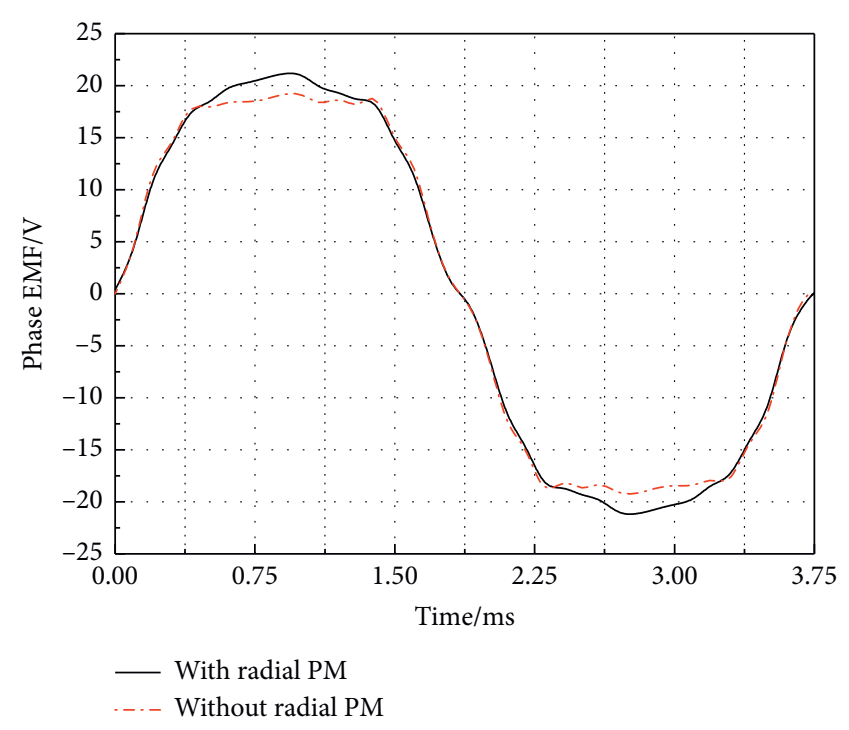

FIgURE 10: EMF of the PMCHEG only with permanent magnetic source.

only $1 / 4$ of the model is calculated. Figure 11 shows the magnetic flux density vector and magnetic flux density module value diagram of the PMCHEG.

It can be seen from Figure 11(a) that the magnetic circuits of the combined PMR and the brushless claw pole EER are independent of each other and form a closed loop through their respective stators. The flux density at the stator yoke of the composite excitation generator is evenly distributed. The flux density at the stator yoke of the PMR and the stator yoke of the EER are both about $1.8 \mathrm{~T}$ in Figure 11(b), which meets the design requirements.

In order to analyze the magnetic field regulation performance of the PMCHEG, the flux density vector diagram under different excitation current is obtained, as shown in Figure 12.

Figure 12(a) shows the magnetic flux density vector diagram with forward current. The electric excitation magnetic flux and the permanent magnetic flux are distributed in parallel inside the stator core, and the direction of two kinds of magnetic lines is the same. The total magnetic flux passing through the air gap is the algebraic sum of the electric magnetic flux and the permanent magnetic flux. The total magnetic flux in the air gap increases, resulting in output voltage to increase. Figure 12(b) shows the magnetic flux density vector diagram with reverse current. The direction of the magnetic flux density vector in two parts is 


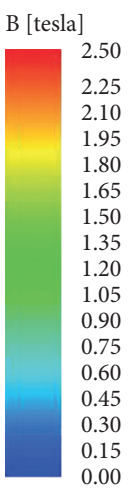

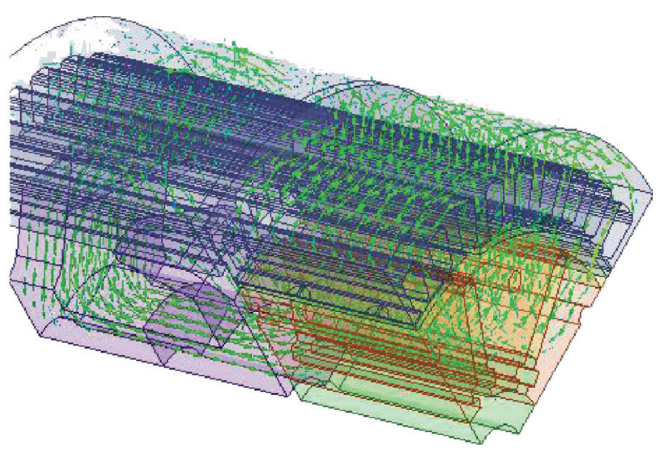

(a)

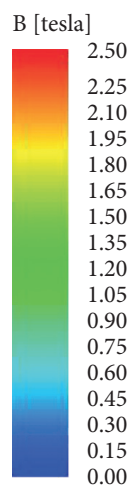

0.00

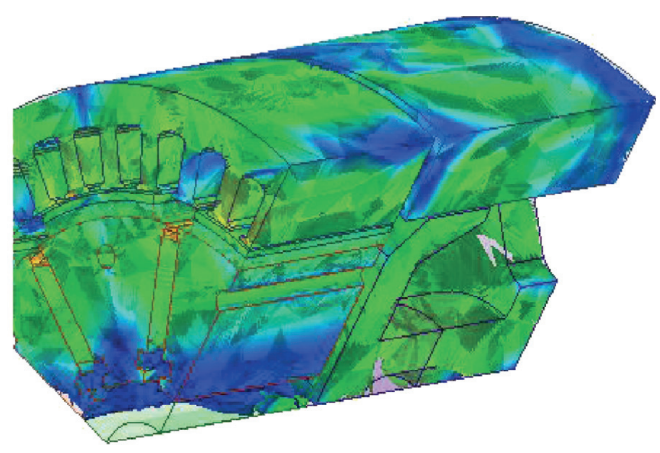

(b)

Figure 11: The field distribution of the PMCHEG. (a) Axial flux density vector diagram. (b) Magnetic flux density module value diagram.

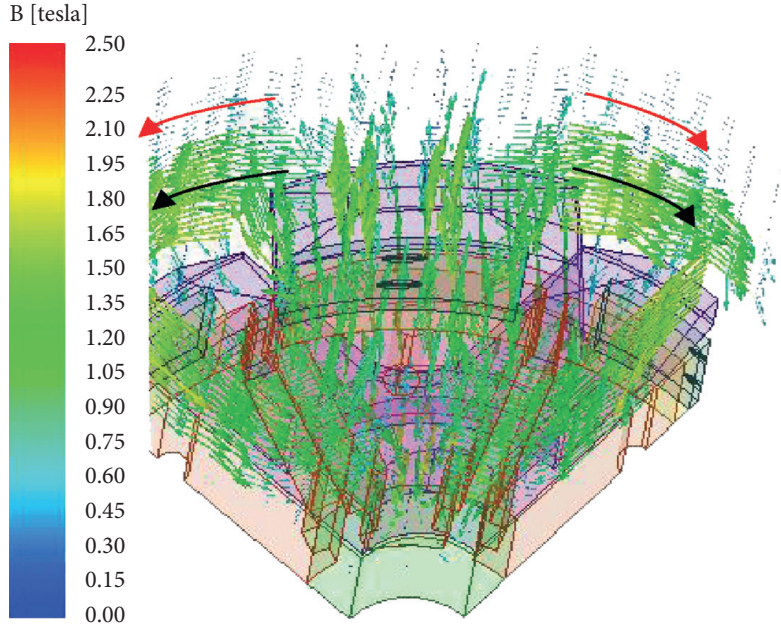

(a)

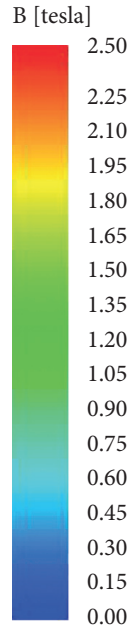

0.00

Figure 12: The flux density vector diagram with different excitation currents. (a) With forward current. (b) With reverse current.

opposite. The magnetic flux in the air gap decreases, resulting in output voltage to decrease.

Figure 13 shows a vector diagram of the magnetic flux density on the axial observation surface. There is almost no leakage between permanent magnetic field and electromagnetic field. The electromagnetic field and permanent magnetic field does not interfere with each other, and the PMCHEG has a good ability to adjust the total air gap magnetic field.

4.2. Analysis of Flux Regulation Characteristics. The radial flux density of the synthetic magnetic field under different excitation current and axial position is shown in Figure 14.

In Figure 14, the air gap flux generated by permanent magnets is constant. The air gap flux generated by the electric excitation winding changes with the field current. As shown in Figures 14(b) and 14(c), the flux of the claw poles away from the PMR is the same direction as that of PMR because they are at the same magnetic pole. With the increase of the forward current, the generator works in the magnetizing state. Figure 14(d) shows the flux of the PMR is the same as that of the adjacent claw pole. Since they are not at the same magnetic pole, the generator is in a weak magnetic state. Comparing 14(a) with 14(b)-14(d), we can also find that the EER has no effect on the magnetic flux of the PMR in the air gap. Under the condition of unsaturated magnetic circuit, the linear adjustment of air gap synthetic magnetic field can be realized by changing the current.

When there are RPMs and no RPMs in the PMR core, the no-load phase EMF of the PMCHEG only with permanent magnetic source is obtained, as shown in Figure 10. Figure 15 shows the no-load phase EMF only with electric excitation source. The no-load phase EMF of the PMCHEG with permanent magnetic source and electric excitation source is obtained in Figure 16.

In Figure 10, when the RPMs are installed in the rotor, the phase EMF waveform tends to be sinusoidal. It is validated that the RPMs can make up for the waveform peak depression of the phase EMF and improve the quality of the 


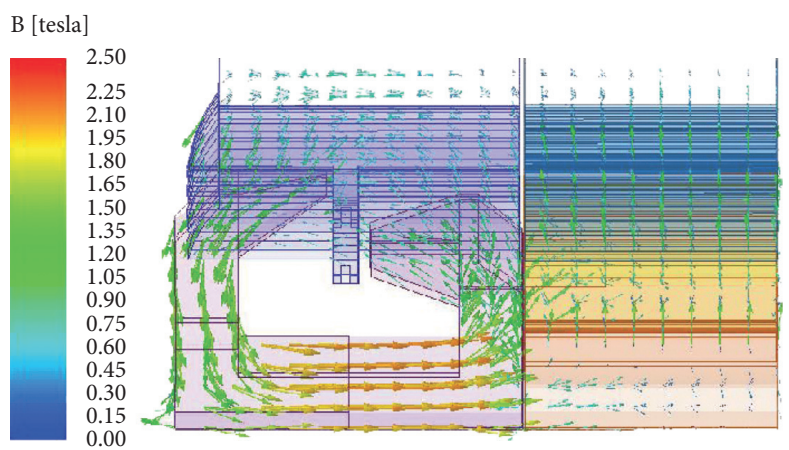

(a)
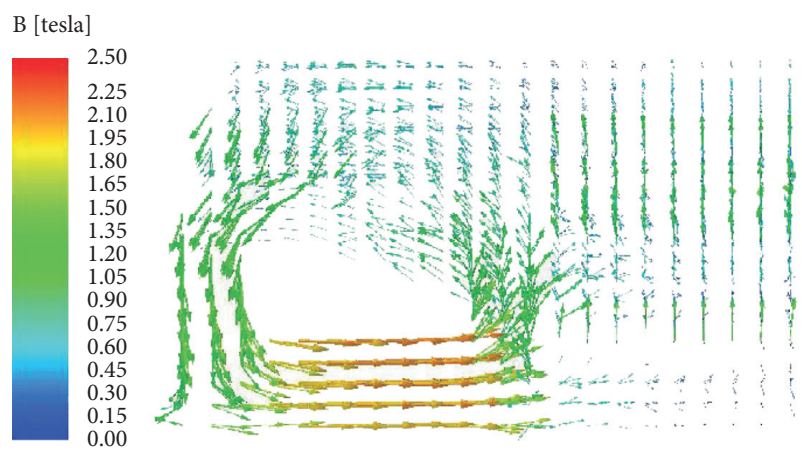

(b)

FIgURE 13: Magnetic flux vector on the axial observation surface.

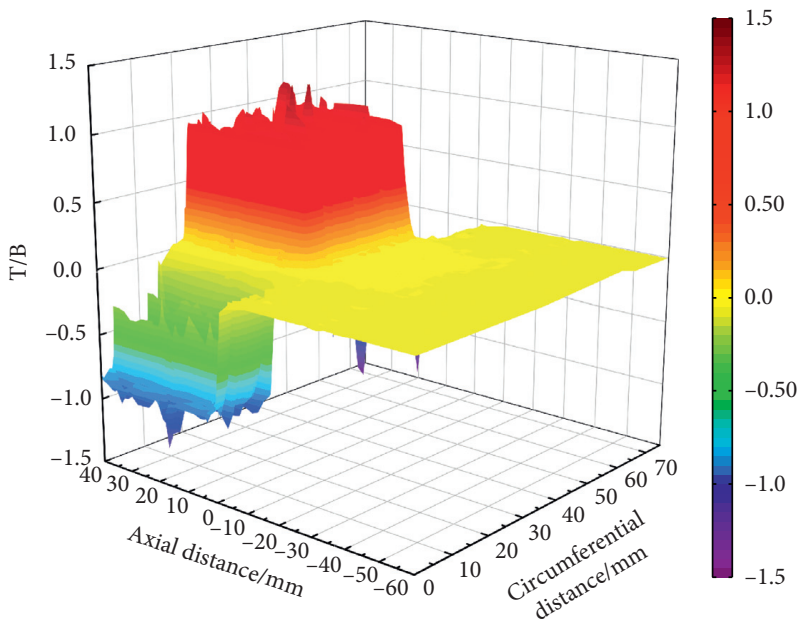

(a)

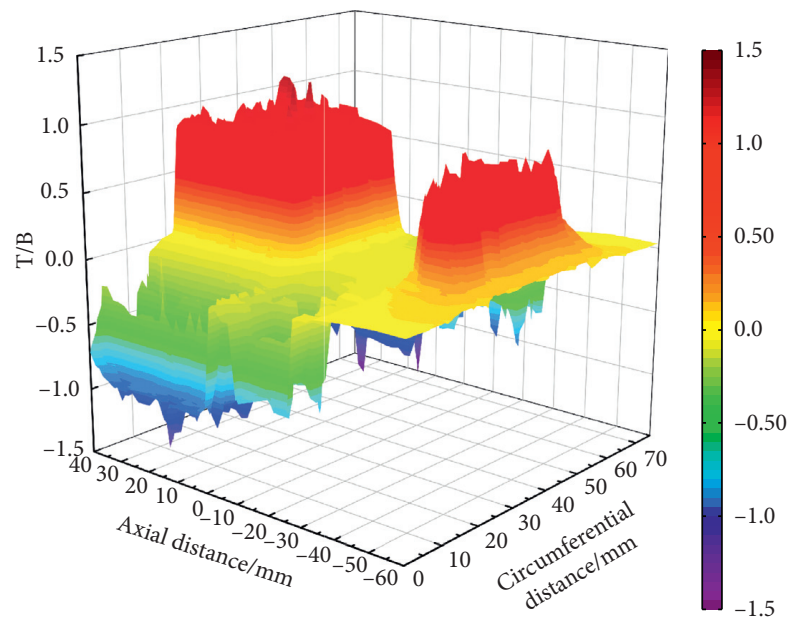

(c)

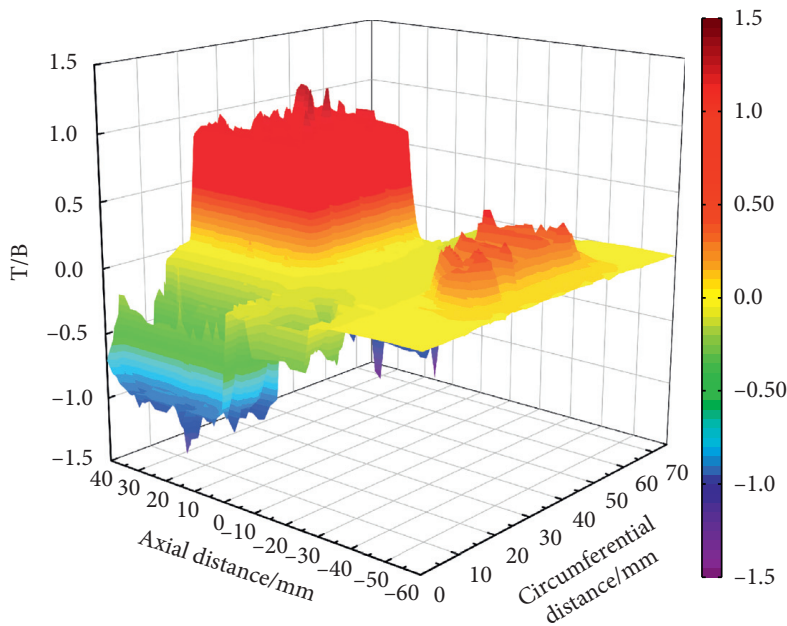

(b)

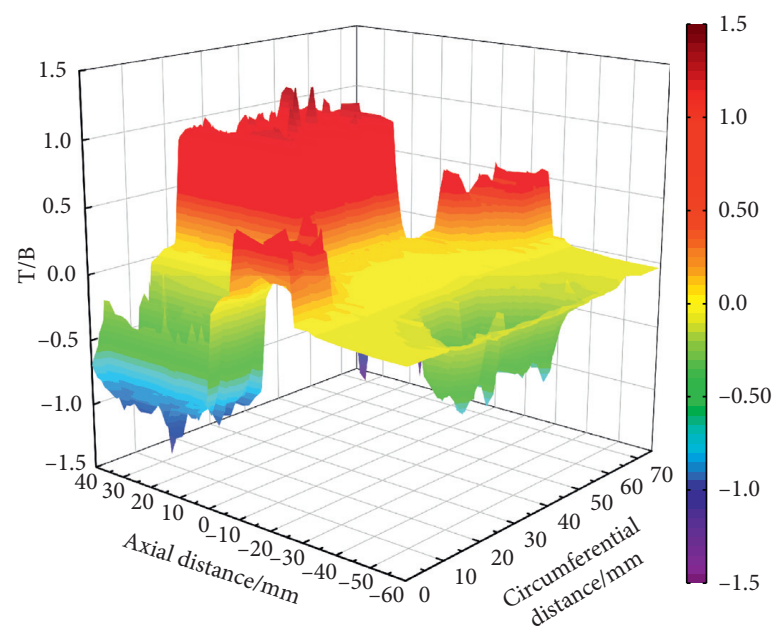

(d)

Figure 14: Radial flux density with excitation current. (a) $I_{\mathrm{e}}=0$ A. (b) $I_{\mathrm{e}}=1 \mathrm{~A}$. (c) $I_{\mathrm{e}}=2 \mathrm{~A}$. (d) $I_{\mathrm{e}}=-2 \mathrm{~A}$.

output voltage. In Figure 15, when the excitation current is $5 \mathrm{~A}$ and $6 \mathrm{~A}$, the two waveforms of the EMF are almost the same. It indicates that the magnetic flux density of claw pole yoke has reached the over-saturation state. At the time, the air gap magnetic flux will not increase, and the induced EMF will not increase. As shown in Figure 16, the value in Figure 16 is equal to the algebraic sum of that in Figures 10 and 15. The PMCHEG can achieve the efficient superposition of 


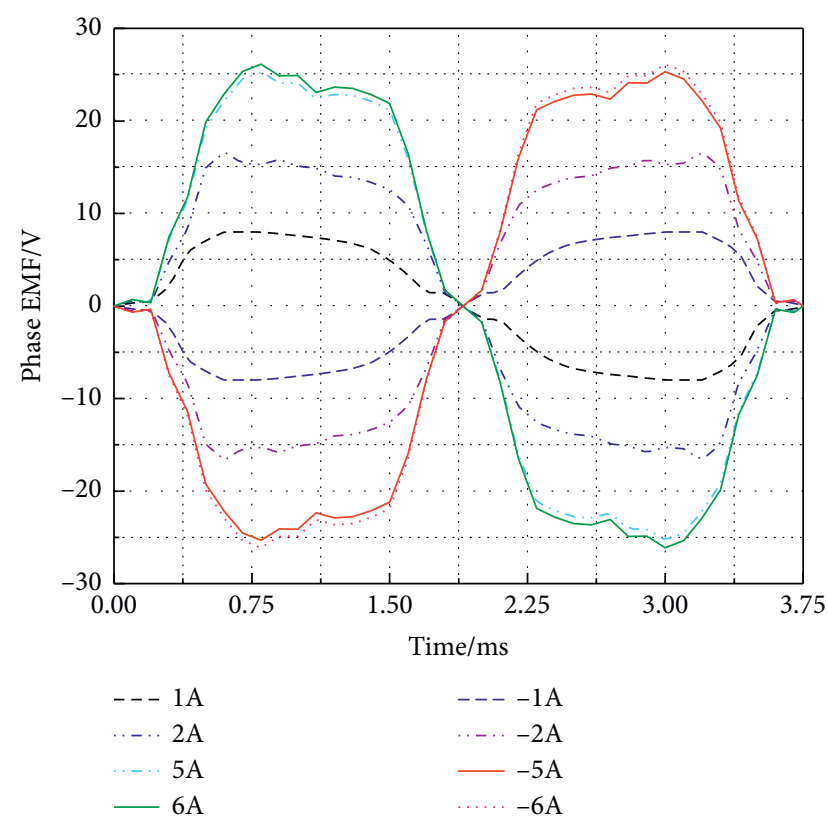

FIGURE 15: EMF of the PMCHEG only with electric excitation source.

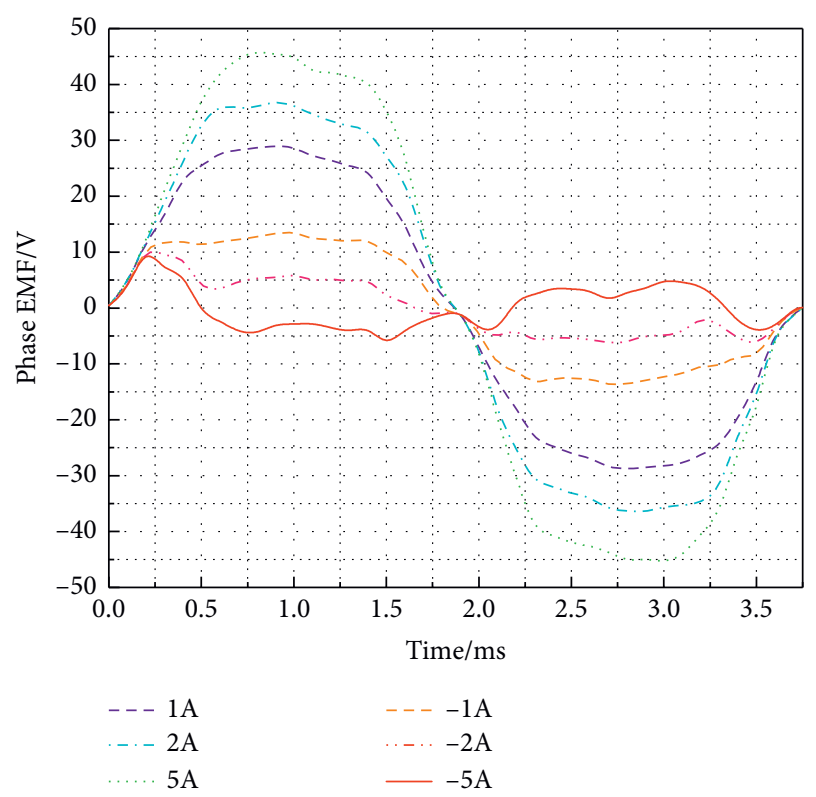

FIGURE 16: EMF of the PMCHEG with PM and electric excitation source.

magnetic field between two different excitation sources. Meanwhile, when the excitation current is $-5 \mathrm{~A}$, the air gap flux is almost demagnetized. It shows that the PMCHEG has strong field weakening ability.

In order to quantify the influence of the magnitude and direction of the excitation current on the axial air gap flux density, the axial flux distribution with different excitation current is shown in Figure 17. In the circumferential direction, the centerlines of three adjacent claw poles are selected and named $\mathrm{C} 1, \mathrm{C} 2$, and C3 magnetic pole in turn. Meanwhile, the corresponding air gap magnetic density is calculated. In the PMR, the flux density at the magnetic poles of $\mathrm{C} 2$ and $\mathrm{C} 3$ is close to $1 \mathrm{~T}$, which proves the combine magnetic pole can improve magnetic flux density in the air gap. The low flux density at the magnetic pole of $\mathrm{C} 1$ is caused by the stator slot. In the EER, when field current is constant, the amplitude of the flux density at the magnetic poles of $\mathrm{C} 1$ and $\mathrm{C} 2$ is equal, but the direction is opposite. However, the amplitude and direction of magnetic flux at the magnetic poles of $\mathrm{C} 1$ and $\mathrm{C} 3$ are the same. When field current changes, the amplitude and direction of the magnetic flux at the magnetic poles of $\mathrm{C} 1$ and $\mathrm{C} 3$ remain constant. To sum up, we can conclude that the average airgap flux density of the whole parallel hybrid excitation brushless generator varies with the excitation current.

Since the excitation current is $2 \mathrm{~A}$, the flux density of the claw pole yoke is not saturated. The air gap flux generated by the EER is in the same direction as that of PMR, and the main flux the PMCHEG is the sum of the flux generated by two rotors. In order to observe the waveform and symmetry of the three-phase induced EMF, the waveforms of the three-phase induced EMF are shown in Figure 18. In Figure 18, the waveforms of the induced EMF of $A, B$, and $C$ phases are symmetrical, and each waveform tends to be sinusoidal. To study the inductance characteristics with various field current, the self-inductance Laa with different field currents in the EER is shown in Figure 19. We can see from Figure 19 that, with the increase of the excitation current, the self-inductance decreases. The forward excitation current has the same effect on the self-inductance as the reverse excitation current.

\section{Performance Test}

Adjusting the excitation currents, the no-load characteristics of the PMCHEG can be obtained at the speed of $4000 \mathrm{r} / \mathrm{min}$, as shown in Figure 20. Because of the neglect of magnetic leakage, iron loss, and processing technology, the experimental results are slightly lower than the simulation results. Keeping the speed, adjusting the excitation current, and adding different load, the load characteristic of the PMCHEG is obtained, as shown in Figure 21. It can be seen that when the excitation current and speed are fixed, the output voltage decreases as the load increases. When the load is fixed, the output voltage increases as the excitation current increases. The PMCHEG has good output performance.

The output stable voltage performance of the developed PMCHEG from low speed to high speed is tested by equipping the PMCHEG with voltage regulator. Three kinds of load power $(475 \mathrm{~W}, 500 \mathrm{~W}$, and $525 \mathrm{~W})$ are considered. The test results are shown in Table 5.

It can be seen from Table 5 that when the speed changes from $2000 \mathrm{r} / \mathrm{min}$ to $4800 \mathrm{r} / \mathrm{min}$ and the load power changes from $475 \mathrm{~W}$ to $525 \mathrm{~W}$, the output voltage is stable between $26.17 \mathrm{~V}$ and $27.69 \mathrm{~V}$. According to the standard, the performance index meets design requirements. 


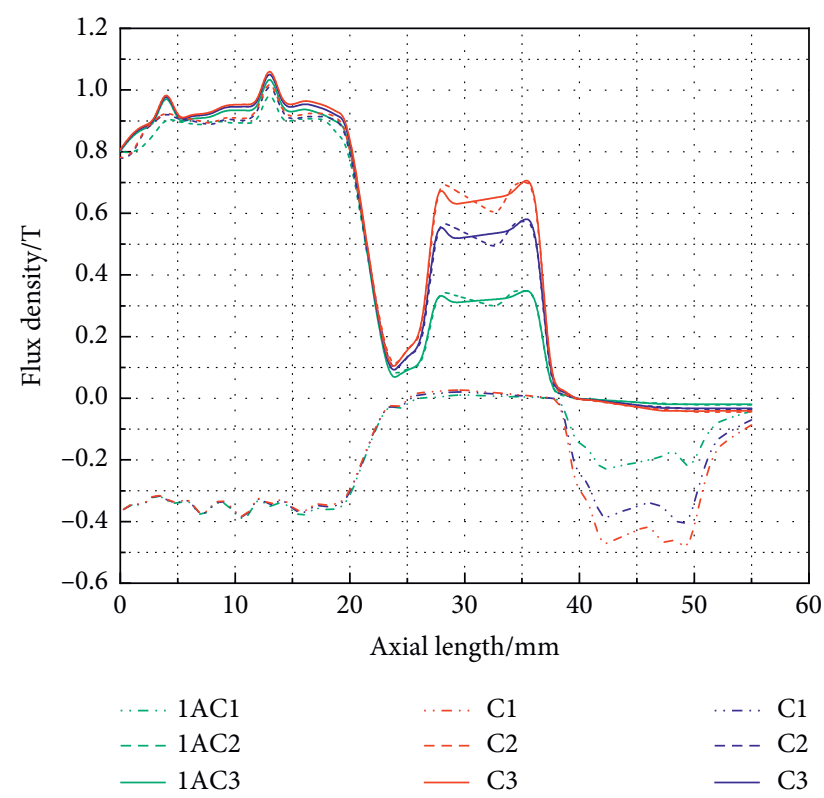

Figure 17: Axial distribution of flux density with excitation current.

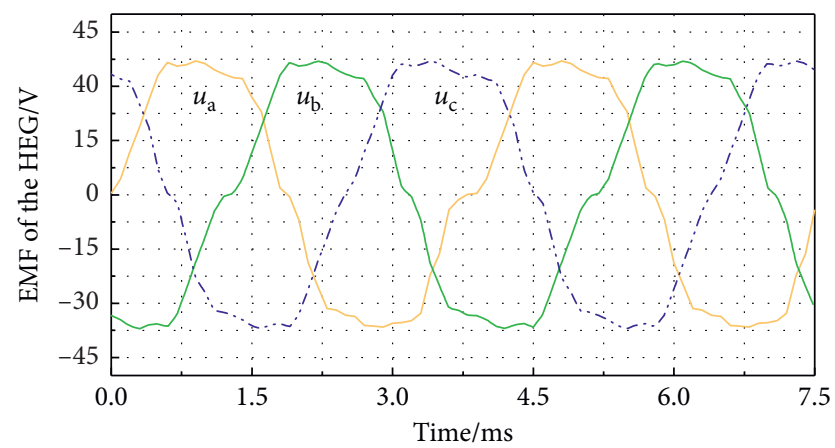

FIgURE 18: Three-phase induced EMF waveforms of the PMCHEG.

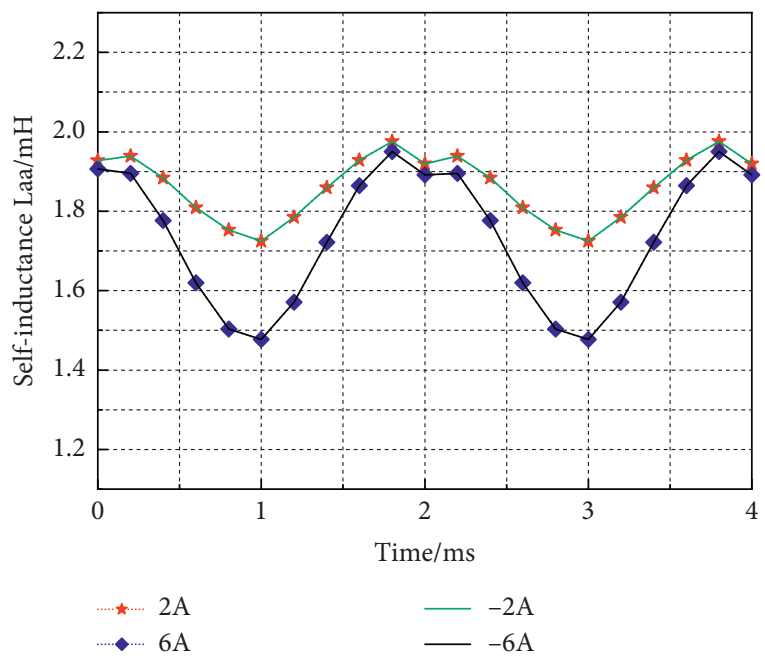

FIGURE 19: The self-inductance Laa with various field currents.

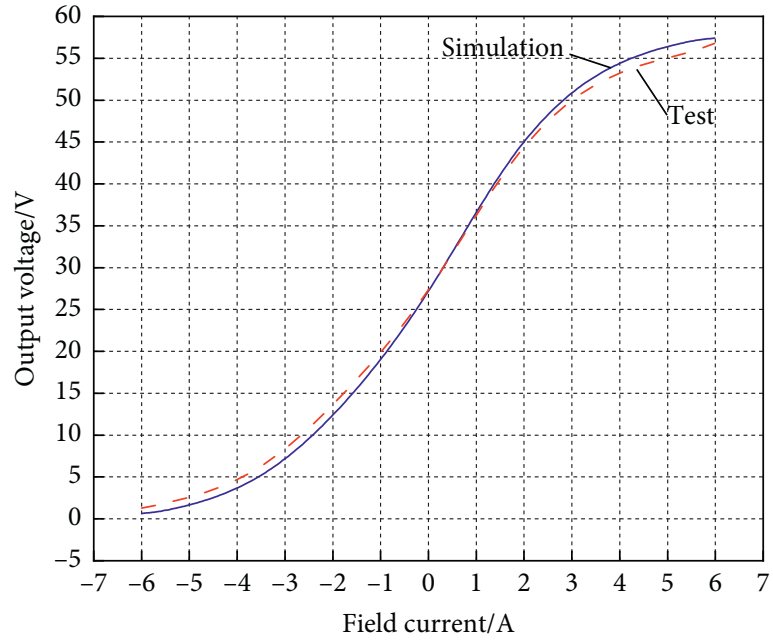

Figure 20: No-load characteristics of the PMCHEG.

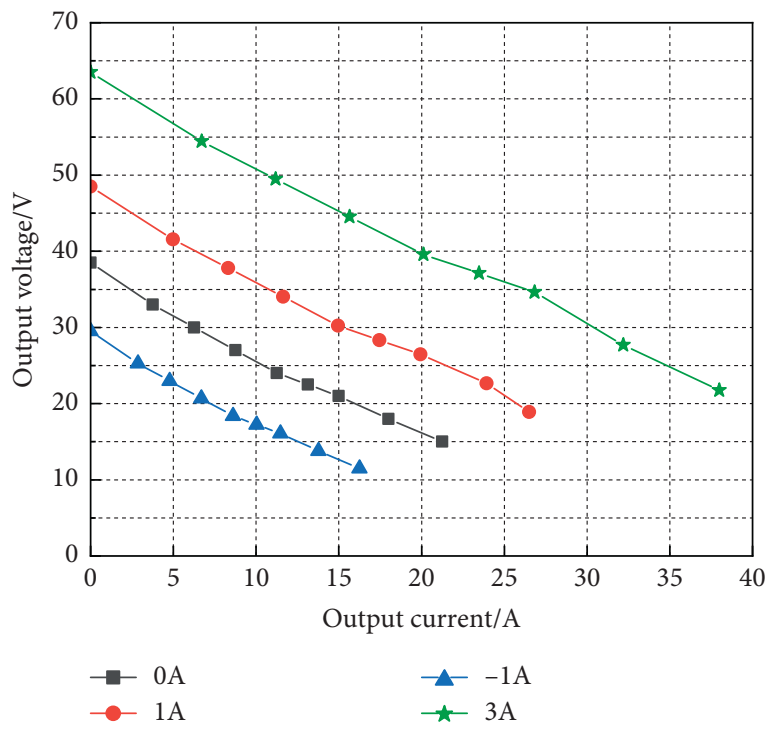

FIGURE 21: Load characteristics of the PMCHEG.

TABLE 5: Test results of output stable voltage.

\begin{tabular}{lcc}
\hline Speed $(\mathrm{r} / \mathrm{min})$ & Load power $(\mathrm{W})$ & Voltage $(\mathrm{V})$ \\
\hline \multirow{3}{*}{2000} & 475 & 26.91 \\
& 500 & 26.53 \\
& 525 & 26.17 \\
\hline \multirow{3}{*}{4000} & 475 & 27.44 \\
& 500 & 26.98 \\
& 525 & 26.42 \\
\hline \multirow{3}{*}{4800} & 475 & 27.69 \\
& 500 & 27.48 \\
& 525 & 27.09 \\
\hline
\end{tabular}




\section{Conclusions}

This paper proposes a new type of a new PMCHEG with surface-mounted and embedded combined PMR and brushless EER for electric vehicle range extender. The electromagnetic design scheme, flux regulation characteristic, and output performance are studied to lay the foundation for application in the field of electric vehicle range extender.

(1) The developed PMCHEG adopts combined rotors, in which PMR and brushless EER are placed side by side on the same axis, the and magnetic fields are combined in air gap in parallel. The design method of the main parameters of the PMCHEG is given in detail. The voltage waveform of two kinds of rotors and their superposition effect are studied by the finite element method, which proves the feasibility and rationality of the parallel combination of two kinds of rotors. When the claw tip pole arc coefficient is 0.45 , the degree of field coupling is the greatest. The induced EMF of two parts can be easier to achieve high efficiency superposition.

(2) Using three-dimensional finite element software, the field distribution under different excitation source and flux regulation characteristic is analyzed. The combine PM and brushless electromagnetic PMCHEG can achieve two-way excitation adjustment well and the effect of complete demagnetization.

(3) When the speed of the PMCHEG changes from $2000 \mathrm{r} / \mathrm{min}$ to $4800 \mathrm{r} / \mathrm{min}$ and the load power changes from $475 \mathrm{~W}$ to $525 \mathrm{~W}$, the output voltage is between $26.17 \mathrm{~V}$ and $27.69 \mathrm{~V}$. Within the operating range, the HEG has good voltage stabilization performance.

The finite element simulation and the prototype experiment have effectively verified the correctness of the design method and performance analysis in this paper.

\section{Data Availability}

The data used to support the findings of this study are included within the article.

\section{Conflicts of Interest}

The authors declare that they have no conflicts of interest.

\section{Acknowledgments}

This research was supported by the National Natural Science Foundation of China (Grant nos. 51875327 and 51975340).

\section{References}

[1] S. Ma, X. Zhang, Q. Du, L. Shi, and X. Meng, "Optimization design of a new type of interior permanent magnet generator for electric vehicle range extender," Journal of Electrical and
Computer Engineering, vol. 2019, Article ID 3108053, 10 pages, 2019.

[2] X. Zhang, Z. Wu, X. Hu, W. Qian, and Z. Li, “Trajectory optimization-based auxiliary power unit control strategy for an extended range electric vehicle," IEEE Transactions on Vehicular Technology, vol. 66, no. 12, pp. 10866-10874, 2017.

[3] J. C. Guan, B. C. Chen, and Y. Y. Wu, "Design of an adaptive power management strategy for range extended electric vehicles," Energies, vol. 12, no. 9, p. 1610, 2019.

[4] X. Zhao, S. Niu, and T. W. Ching, "Design and analysis of a new brushless electrically excited claw-Pole generator for hybrid electric vehicle," IEEE Transactions on Magnetics, vol. 54, no. 11, Article ID 8108505, 2018.

[5] Y. Xia, Z. Wen, Z. Zhu, S. Zhong, Y. Chen, and J. Zhang, "Research on a hybrid excitation PM synchronous generator with stator third harmonic winding excitation," Iet Electric Power Applications, vol. 14, no. 3, pp. 418-425, 2020.

[6] C. Ye, Y. Du, J. Yang, X. Liang, F. Xiong, and W. Xu, "Research of an axial flux stator partition hybrid excitation brushless synchronous generator," IEEE Transactions on Magnetics, vol. 54, no. 11, Article ID 8204304, 2018.

[7] S. Zhu, C. Liu, K. Wang, X. Yuan, Y. Hu, and Y. Ning, "Magnetic field distribution and operating characteristics of a hybrid excitation generator based on integrated brushless excitation," IEEE Transactions on Magnetics, vol. 52, no. 9, Article ID 8107512, 2016.

[8] Z. Shushu, L. Chuang, N. Yinhang, and T. Jie, "A two-stage brushless excitation method for hybrid excitation synchronous generator," IEEE Transactions on Magnetics, vol. 51, no. 6, Article ID 8105411, 2015.

[9] E. Yildiriz and G. Onbilgin, "Comparative study of new axial field permanent magnet hybrid excitation machines," Iet Electric Power Applications, vol. 11, no. 7, pp. 1347-1355, 2017.

[10] W. Hu, X. Zhang, Y. Lei, Q. Du, L. Shi, and G. Liu, “Analytical model of air-gap field in hybrid excitation and interior permanent magnet machine for electric logistics vehicles," IEEE Access, vol. 8, pp. 148237-148249, 2020.

[11] F. G. Capponi, G. Borocci, G. D. Donato, and F. Caricchi, "Flux regulation strategies for hybrid excitation synchronous machines," IEEE Transactions on Industry Applications, vol. 51, no. 5, pp. 3838-3847, 2015.

[12] Y. Wu, L. Sun, Z. Zhang, Z. Miao, and C. Liu, "Analysis of torque characteristics of parallel hybrid excitation machine drives with sinusoidal and rectangular current excitations," IEEE Transactions on Magnetics, vol. 54, no. 11, Article ID 8207205, 2018.

[13] Y. Liu, Z. Zhang, C. Wang, and H. Gao, "Optimization and performance improvement of a hybrid excitation synchronous machine with modular magnetic-shunting rotor," IEEE Transactions on Industrial Electronics, vol. 67, no. 6, pp. 4381-4390, 2020.

[14] S. Cai, Z.-Q. Zhu, C. Wang, J.-C. Mipo, and S. Personnaz, “A novel fractional slot non-overlapping winding hybrid excited machine with consequent-Pole PM rotor," IEEE Transactions on Energy Conversion, vol. 35, no. 3, pp. 1628-1637, 2020.

[15] D. Li, R. Qu, J. Li, and W. Xu, "Consequent-Pole toroidalwinding outer-rotor vernier permanent-magnet machines," IEEE Transactions on Industry Applications, vol. 51, no. 6, pp. 4470-4481, 2015.

[16] J. Li and K. Wang, "Analytical determination of optimal PM-arc ratio of consequent-pole permanent magnet machines," IEEE/ ASME Transactions on Mechatronics, vol. 23, no. 5, pp. 2168-2177, 2018.

[17] B. Gaussens, E. Hoang, M. Lecrivain, P. Manfe, and M. Gabsi, "A hybrid-excited flux-switching machine for high-speed DC- 
alternator applications," IEEE Transactions on Industrial Electronics, vol. 61, no. 6, pp. 2976-2989, 2014.

[18] J. T. Chen, Z. Q. Zhu, S. Iwasaki, and R. P. Deodhar, "A novel hybrid-excited switched-flux brushless AC machine for EV/ HEV applications," IEEE Transactions on Vehicular Technology, vol. 60, no. 4, pp. 1365-1373, 2011.

[19] Y. Yang, X. Wang, and Z. Zhang, "Performance analysis of novel single-phase parallel hybrid-excited flux-switching machine," IEEE Transactions on Magnetics, vol. 54, no. 12, Article ID 8110813, 2018.

[20] L. Huang, M. Hu, J. Liu, H. Yu, C. Zeng, and Z. Chen, "Electromagnetic design of a 10-kW-Class flux-switching linear superconducting hybrid excitation generator for wave energy conversion," IEEE Transactions on Applied Superconductivity, vol. 27, no. 4, Article ID 5201706, 2017.

[21] G. Zhang, W. Hua, M. Cheng, J. Liao, K. Wang, and J. Zhang, "Investigation of an improved hybrid-excitation fluxswitching brushless machine for HEV/EV applications," IEEE Transactions on Industry Applications, vol. 51, no. 5, pp. 3791-3799, 2015.

[22] C. Wang, Z. Zhang, Y. Liu, and H. Gao, "Mechanical design and analysis of a high-torque modular hybrid excitation synchronous machine for electric vehicle propulsion applications," IEEE Transactions on Vehicular Technology, vol. 69, no. 9, pp. 9624-9633, 2020.

[23] T. Kosaka, M. Sridharbabu, M. Yamamoto, and N. Matsui, "Design studies on hybrid excitation motor for main spindle drive in machine tools," IEEE Transactions on Industrial Electronics, vol. 57, no. 11, pp. 3807-3813, 2010.

[24] Z. Zhang, J. Dai, C. Dai, and Y. Yan, "Design considerations of a hybrid excitation synchronous machine with magnetic shunt rotor," IEEE Transactions on Magnetics, vol. 49, no. 11, pp. 5566-5573, 2013.

[25] Y. Liu, Z. Zhang, C. Wang, W. Geng, and H. Wang, "Electromagnetic performance analysis of a new hybrid excitation synchronous machine for electric vehicle applications," IEEE Transactions on Magnetics, vol. 54, no. 11, Article ID 8204804, 2018.

[26] X. Zhang, Q. Du, S. Ma et al., "Permeance analysis and calculation of the double-radial rare-earth permanent magnet voltage-stabilizing generation device," IEEE Access, vol. 6, pp. 23939-23947, 2018.

[27] H. Geng, X. Zhang, Y. Zhang et al., "Development of brushless claw Pole electrical excitation and combined permanent magnet hybrid excitation generator for vehicles," Energies, vol. 13, no. 18, pp. 1-13, 2020.

[28] J. Y. Alsawalhi and S. D. Sudhoff, "Design optimization of asymmetric salient permanent magnet synchronous machines," IEEE Transactions on Energy Conversion, vol. 31, no. 4, pp. 1315-1324, 2016.

[29] Y. Liu, Z. Zhang, and X. Zhang, "Design and optimization of hybrid excitation synchronous machines with magnetic shunting rotor for electric vehicle traction applications," IEEE Transactions on Industry Applications, vol. 53, no. 6, pp. 5252-5261, 2017.

[30] L. Sun, Z. Zhang, L. Yu, and X. Gu, "Development and analysis of a new hybrid excitation brushless DC generator with flux modulation effect," IEEE Transactions on Industrial Electronics, vol. 66, no. 6, pp. 4189-4198, 2019.

[31] J. Pang, W. Liu, Z. Wei, C. Sun, N. Jiao, and X. Han, "Online diode fault detection in rotating rectifier of the brushless synchronous starter generator," IEEE Transactions on Industrial Informatics, vol. 16, no. 11, pp. 6943-6951, 2020.
[32] X. Zhang, Q. Du, S. Ma, J. Xu, and H. Geng, "Development of hybrid excitation generator for vehicles," Qiche Gongcheng/ Automotive Engineering, vol. 39, pp. 822-826, 2017. 